\title{
Article \\ Modifying Electronic and Elastic Properties of 2-Dimensional [110] Diamond by Nitrogen Substitution
}

\author{
Teerachote Pakornchote ${ }^{1,2}\left(\mathbb{D}\right.$, Annop Ektarawong ${ }^{1,2}\left(\mathbb{D}\right.$, Udomsilp Pinsook ${ }^{1,2}$ a and Thiti Bovornratanaraks $1,2, * \mathbb{C}$ \\ 1 Extreme Condition Physics Research Laboratory, Physics of Energy Materials Research Unit, \\ Department of Physics, Faculty of Science, Chulalongkorn University, Bangkok 10330, Thailand; \\ t.pakornchote@gmail.com (T.P.); annop.e@chula.ac.th (A.E.); udomsilp.p@chula.ac.th (U.P.) \\ 2 Thailand Center of Excellence in Physics, Commission on Higher Education, 328 Si Ayutthaya Road, \\ Bangkok 10400, Thailand \\ * Correspondence: thiti.b@chula.ac.th
}

Citation: Pakornchote, T.;

Ektarawong, A.; Pinsook, U.;

Bovornratanaraks, T. Modifying Electronic and Elastic Properties of 2-Dimensional [110] Diamond by Nitrogen Substitution. C 2021, 7, 8 . https://doi.org/10.3390/c7010008

Received: 15 December 2020 Accepted: 16 January 2021 Published: 21 January 2021

Publisher's Note: MDPI stays neutral with regard to jurisdictional clai$\mathrm{ms}$ in published maps and institutional affiliations.

Copyright: () 2021 by the authors. Licensee MDPI, Basel, Switzerland. This article is an open access article distributed under the terms and conditions of the Creative Commons Attribution (CC BY) license (https:// creativecommons.org/licenses/by/ $4.0 /)$.

\begin{abstract}
One type of two-dimensional diamonds that are derived from [111] direction, so-called diamane, has been previously shown to be stabilized by $\mathrm{N}$-substitution, where the passivation of dangling bonds is no longer needed. In the present work, we theoretically demonstrated that another type of two-dimensional diamonds derived from [110] direction exhibiting a washboard conformation can also be stabilized by $\mathrm{N}$-substitution. Three structural models of washboard-like carbon nitrides with compositions of $\mathrm{C}_{6} \mathrm{~N}_{2}, \mathrm{C}_{5} \mathrm{~N}_{3}$, and $\mathrm{C}_{4} \mathrm{~N}_{4}$ are studied together with the fully hydrogenated washboard-like diamane $\left(\mathrm{C}_{8} \mathrm{H}_{4}\right)$. The result shows that the band gap of this type structure is only open the dangling bonds that are entirely diminished through N-substitution. By increasing the $\mathrm{N}$ content, the $C_{11}$ and $C_{22}$ are softer and the $C_{33}$ is stiffer where their bulk modulus are in the same order, which is approximately $550 \mathrm{GPa}$. When comparing with the hydrogenated phase, the N-substituted phases have higher elastic constants and bulk modulus, suggesting that they are possibly harder than the fully hydrogenated diamane.
\end{abstract}

Keywords: diamane; carbon nitrides; 2D materials; Ab initio; superhard materials; semiconductor

\section{Introduction}

Diamond, a carbon allotrope, is a material that has been reported to be the first hardest material and it also possesses the highest thermal conductivity. Its hardness originates from characteristic of $\mathrm{sp}^{3}$ hybridization of $\mathrm{C}$ atoms, which has a tetrahedral symmetry with high bonding strength. In fact, the $\mathrm{sp}^{2}$ hybridization of $\mathrm{C}$ atoms is stronger than $\mathrm{sp}^{3}$ hybridization, for example, graphene. Graphene can persist with a high load of an indentation without breaking bonds showing remarkably high tensile strength [1]; however, its hardness cannot be measured. Other $\mathrm{sp}^{3}$ carbon allotrope, i.e., lonsdaleite, is predicted to be harder than diamond, but its existence is under discussion [2-4].

Since the two-dimensional (2D) materials has come into the spot light, the path for creating a thin diamond-like film has been examined [5,6]. A 2D diamond that is derived from the bulk diamond thinned down in [111] direction or diamane is a promising material for adopting the property of its bulk counterpart, diamond, but its thickness is only $4 \mathrm{C}$ atoms stacking [7-10]. In order to create the $\mathrm{sp}^{3}$ carbon film, the layers of the $\mathrm{sp}^{2}$ carbon films, e.g., bilayer graphene and few-layer graphene, must be closer, because its interlayer distance is much larger than a bond length of the $\mathrm{sp}^{3}$ carbon film [11]. The $\mathrm{sp}^{2}$ carbon film can be indented by a sharp indenter creating the $\mathrm{sp}^{3}$ hybridization and showing that the indented multi-layer graphene is harder if its number of layers is fewer $[10,12,13]$. Moreover, diamane can also be synthesized at high pressure, where it is expected to be stable at $5 \mathrm{GPa}[6,14]$.

Even though the diamane can be created, its $\mathrm{sp}^{3}$ hybridization cannot persist without an external auxiliary i.e., indentation, high-pressure $[6,10]$. The surfaces of diamane that are 
full of dangling bonds need to be passivated with atoms or molecules; otherwise, diamane will transform back to a $\mathrm{sp}^{2}$ carbon film [11]. Several works have theoretically studied on the stability of diamane that is passivated by other atoms and molecules and also its band gap and thermal conductivity, depending on passivating molecules $[15,16]$. The diamane can be synthesized by exposing a bilayer graphene in order to chemically react with $\mathrm{H}$ or $\mathrm{F}$ atoms [17-20].

Lately, we have shown that the passivation of dangling bonds of the surficial $\mathrm{C}$ atoms is not the only method for stabilizing diamane. It can also be stabilized by substituting the $\mathrm{N}$ atom, which has one electron more than $\mathrm{C}$ atoms on its surfaces [21]. The remaining electrons that form lone electron pairs behave like the passivation that stabilizes the structure and opens a band gap. Moreover, the surface reconstruction that occurs on the outermost layer to have a particular structure can promote the stabilization of the $\mathrm{sp}^{3}$ structure of the 2D carbon [21-23]. Beneficially, the reconstructing surface also enhances a magnetism of the structure, which is typically absent in diamane [21,24].

In this work, $2 \mathrm{D}$ diamond-like carbon nitrides $\left(\mathrm{C}_{8-x} \mathrm{~N}_{x}\right)$, where their structures are derived from the structure of diamond thinned down in [110] direction until it has eight atoms in a unit cell (see Figure 1), are studied where $x=2,3,4$. Because its surfaces are washboard conformations [25], it will be represented as W-diamane for a phase with $x=0$ and $\mathrm{N}$-subsituted $\mathrm{W}$-diamanes for phases with $x=2,3,4$. Their elastic and electronic properties are investigated, due to a number of $\mathrm{N}$ atoms in the structure. It will be shown that an accretion of $\mathrm{N}$ atoms on the surfaces of $\mathrm{W}$-diamane improves the dynamical stability and enhances the stiffness of the structure, which are even stiffer than hydrogenated 2D diamond.

a

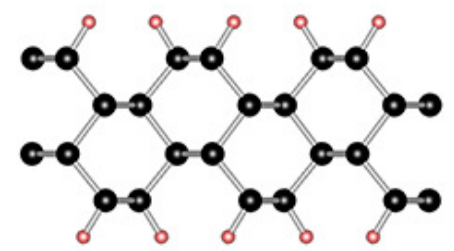

c

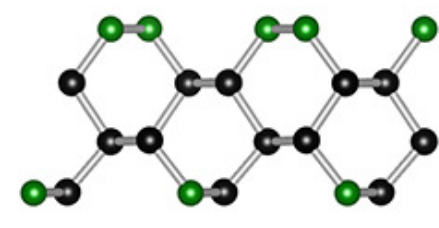

b

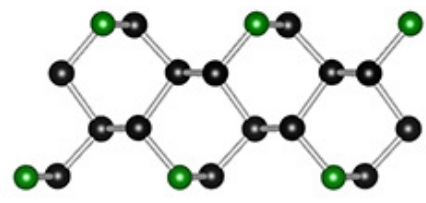

d

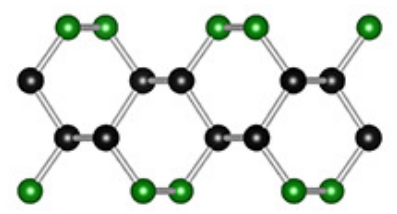

e

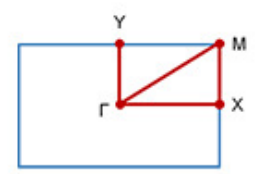

Figure 1. Structures of (a) $\mathrm{C}_{8} \mathrm{H}_{4}$, (b) $\mathrm{C}_{6} \mathrm{~N}_{2}$, (c) $\mathrm{C}_{5} \mathrm{~N}_{3}$, and (d) $\mathrm{C}_{4} \mathrm{~N}_{4}$ where the black, red and green balls are $\mathrm{C}$, $\mathrm{H}$, and $\mathrm{N}$ atoms, respectively. The $\theta$ indicates to the angle measured between surficial and inner atoms. (e) Paths between high symmetry points in the Brillouin zone.

\section{Computational Method}

The VASP package [26,27], based on the density functional theory, was performed in order to study the properties of the $2 \mathrm{D}$ diamond. The projector augmented-wave method [28], which is an efficient method for reducing a cumbersome calculation of the core electrons, was used for the pseudopotential. The exchange-correlation functionals, PerdewBurke-Ernzerhof (PBE) and Heyd-Scuseria-Ernzerhof (HSE06), were employed [29,30]. The former was used for the structural relaxation in order to find the optimum structural parameters and atomic positions at $0 \mathrm{GPa}$ and $0 \mathrm{~K}$, evaluating the elastic constants, and calculating phonon modes. The latter was used for the electronic density of states (DOS) and band structure calculations. 
The energy cutoff was set as $600 \mathrm{eV}$ in all calculations. The k-point mesh was $11 \times 5 \times 1$ for the relaxation and calculation of the elastic constants. In order to neglect the interaction between layers of 2D materials, the $c$-axis of every structure was set to be $20 \AA$ at the start of the relaxation and asserted to be larger than $15 \AA$ after the relaxation. The phonon modes were calculated while using Phonopy package [31] with $5 \times 3 \times 1$ supercell and $1 \times 1 \times 1$ k-point mesh. Every DOS was calculated by using the tetrahedron method to integrate over the Brillouin zone [32].

In calculations of the elastic constants, lattice parameters of the studied structures were applied by $1 \%$ and $2 \%$ compressive and tensile strains, while the atomic positions were relaxed. For the elastic constants corresponding to a direction that is perpendicular to the layer, z-positions of the top and bottom atoms were fixed during the atomic relaxation to constrain a $c$-parameter of the strained lattice, which is a distance between top and bottom atoms. Otherwise, the top and bottom atoms would be relaxed to new z-positions, yielding unintended strained lattice, which should be fixed to be $1 \%$ or $2 \%$ strains [21].

\section{Results}

\subsection{2-Dimensional Structures}

The structure of $\mathrm{W}$-diamane is relaxed without any passivations or $\mathrm{N}$ substitutions. As expected, W-diamane with entire dangling bonds on its surfaces cannot be stabilized after relaxation, but it can be stabilized if the dangling bonds are passivated through hydrogenation $\left(\mathrm{C}_{8} \mathrm{H}_{4}\right.$, see Figure 1a). We find that, instead of hydrogenation, the substitution of $\mathrm{N}$ atoms for surficial $\mathrm{C}$ atoms can also result in the structural stabilization of $\mathrm{W}$-diamane. Nevertheless, the substitution is needed on both surfaces of W-diamane in order to keep the washboard-like shape stable on two sides after relaxation. For $\mathrm{C}_{7} \mathrm{~N}$, an amount of $\mathrm{N}$ atoms is not enough to substitute on both of its surfaces, hence it is not considered. Noting that the studied phases have $\mathrm{N}$ atoms arranging in highly order by considering the substitution in the unit cell of $\mathrm{W}$-diamane with eight atoms, while the configurational disorder of $\mathrm{C}$ and $\mathrm{N}$ atoms in $\mathrm{W}$-diamane is beyond the scope and, thus, not considered in this work.

Table 1 reports the relaxed structures of $\mathrm{C}_{8} \mathrm{H}_{4}, \mathrm{C}_{6} \mathrm{~N}_{2}, \mathrm{C}_{5} \mathrm{~N}_{3}$, and $\mathrm{C}_{6} \mathrm{~N}_{4}$. Howeve, noting that $c$-axes were not fixed during the relaxation, the relaxed $c$-axes are long enough to keep all of structures as 2D materials. The lattice parameters, $a$ and $b$, are smaller as the number of $\mathrm{N}$ atoms increasing, while their thicknesses from top to bottom layers $\left(d_{0}\right)$ are thicker, as shown in Table 1. Two parameters presenting the characteristics of the structures are bond length and bond angle. Typically, the C-N and N-N bond lengths are shorter than $\mathrm{C}-\mathrm{C}$ bond length, so average bond lengths of $\mathrm{N}$-substituted $\mathrm{W}$-diamanes are shorter if the number of $\mathrm{N}$ atoms is higher. For an illustration, the average $\mathrm{C}-\mathrm{C}$ bond length of $\mathrm{C}_{8} \mathrm{H}_{4}$ is $1.558 \AA$, while the average bond lengths of $\mathrm{C}_{6} \mathrm{~N}_{2}, \mathrm{C}_{5} \mathrm{~N}_{3}$, and $\mathrm{C}_{4} \mathrm{~N}_{4}$ are 1.508, 1.495, and $1.506 \AA$, respectively. On the contrary, bond angles of atoms between layers of $\mathrm{C}_{6} \mathrm{~N}_{2}, \mathrm{C}_{5} \mathrm{~N}_{3}$, and $\mathrm{C}_{4} \mathrm{~N}_{4}$ (see Figure 1 ) are $101.85^{\circ}, 110.08^{\circ}$, and $112.37^{\circ}$, respectively, showing an upward trend that corresponds to the number of $\mathrm{N}$ atoms.

Figure 2 shows phonon dispersions of hydrogenated and N-substituted W-diamanes, where the negative value of phonon frequency represents an imaginary mode of the phonon. $\mathrm{C}_{8} \mathrm{H}_{4}$ and $\mathrm{C}_{4} \mathrm{~N}_{4}$, which are fully passivated and $\mathrm{N}$ substituted, respectively, have no imaginary modes, so they are dynamically stable. On the other hand, $\mathrm{C}_{6} \mathrm{~N}_{2}$ and $\mathrm{C}_{5} \mathrm{~N}_{3}$, which are partially $\mathrm{N}$-substituted, have some amounts of the imaginary phonon, so they are not dynamically stable. Figure $2 \mathrm{~b}-\mathrm{d}$ show the evolution of the imaginary phonon, which is fewer with respect to the number of $\mathrm{N}$ substitution in W-diamanes. This is clearly indicating that the stabilization of such a structure can be promoted by suppressing a number of the dangling bonds on the surfaces. 
Table 1. The relaxed structures of $\mathrm{C}_{8} \mathrm{H}_{4}, \mathrm{C}_{6} \mathrm{~N}_{2}$ and $\mathrm{C}_{4} \mathrm{~N}_{4}$ are reported. The atomic species with subscript sf and in indicate an atom on the surface and atom in the inner layer, respectively.

\begin{tabular}{|c|c|c|c|c|c|}
\hline Phase & Space Group & Lattice Parameters & Atomic Species & Wyckoff Sites & Positions \\
\hline $\mathrm{C}_{8} \mathrm{H}_{4}$ & Pmna & $\begin{array}{c}a=2.509 \AA \\
b=3.762 \AA \\
c=23.282 \AA \\
d_{0}=5.57 \AA\end{array}$ & $\begin{array}{c}\mathrm{C}_{\text {in }} \\
\mathrm{C}_{\mathrm{sf}} \\
\mathrm{H}\end{array}$ & $\begin{array}{l}4 \mathrm{~h} \\
4 \mathrm{~h} \\
4 \mathrm{~h}\end{array}$ & $\begin{array}{l}(0.000,0.626,0.027) \\
(0.000,0.367,0.079) \\
(0.000,0.519,0.120)\end{array}$ \\
\hline $\mathrm{C}_{6} \mathrm{~N}_{2}$ & $P m n 2_{1}$ & $\begin{array}{c}a=2.428 \AA \\
b=3.614 \AA \\
c=17.521 \AA \\
d_{0}=3.58 \AA\end{array}$ & $\begin{array}{l}\mathrm{C}_{\mathrm{in}_{1}} \\
\mathrm{C}_{\mathrm{in}_{2}} \\
\mathrm{C}_{\mathrm{sf}} \\
\mathrm{N}_{\mathrm{sf}} \\
\end{array}$ & $\begin{array}{l}2 \mathrm{a} \\
2 \mathrm{a} \\
2 \mathrm{a} \\
2 \mathrm{a}\end{array}$ & $\begin{array}{l}(0.000,0.616,0.538) \\
(0.000,0.359,0.463) \\
(0.000,0.333,0.601) \\
(0.000,0.628,0.397) \\
\end{array}$ \\
\hline $\mathrm{C}_{5} \mathrm{~N}_{3}$ & $P m$ & $\begin{array}{c}a=2.408 \AA \\
b=3.529 \AA \\
c=18.239 \AA \\
\alpha=90.13^{\circ} \\
d_{0}=3.69 \AA\end{array}$ & $\begin{array}{c}\mathrm{C}_{\mathrm{in}_{1}} \\
\mathrm{C}_{\mathrm{in}_{2}} \\
\mathrm{C}_{\mathrm{in}_{3}} \\
\mathrm{C}_{\mathrm{in}_{4}} \\
\mathrm{C}_{\mathrm{sf}} \\
\mathrm{N}_{\mathrm{sf}_{1}} \\
\mathrm{~N}_{\mathrm{sf}_{2}} \\
\mathrm{~N}_{\mathrm{sf}_{1}}\end{array}$ & & $\begin{array}{l}(0.000,0.126,0.154) \\
(0.500,0.377,0.155) \\
(0.500,0.624,0.226) \\
(0.000,0.881,0.226) \\
(0.000,0.851,0.092) \\
(0.500,0.636,0.090) \\
(0.500,0.374,0.293) \\
(0.000,0.190,0.292)\end{array}$ \\
\hline $\mathrm{C}_{4} \mathrm{~N}_{4}$ & Pmna & $\begin{array}{c}a=2.391 \AA \\
b=3.468 \AA \\
c=21.189 \AA \\
d_{0}=3.76 \AA\end{array}$ & $\begin{array}{l}C_{\text {in }} \\
N_{\text {sf }}\end{array}$ & $\begin{array}{l}4 \mathrm{~h} \\
4 \mathrm{~h}\end{array}$ & $\begin{array}{l}(0.000,0.378,0.031) \\
(0.000,0.625,0.089)\end{array}$ \\
\hline
\end{tabular}

a

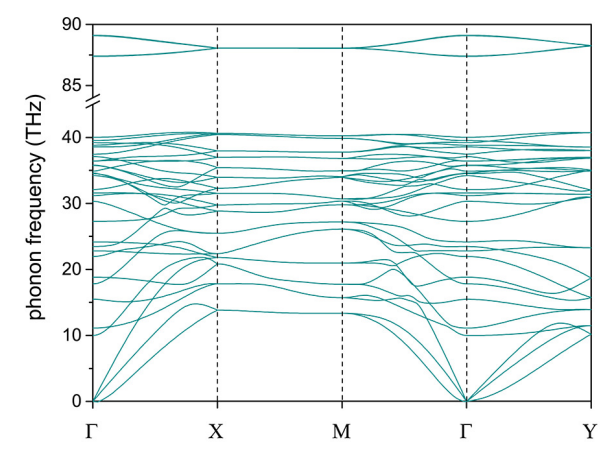

C

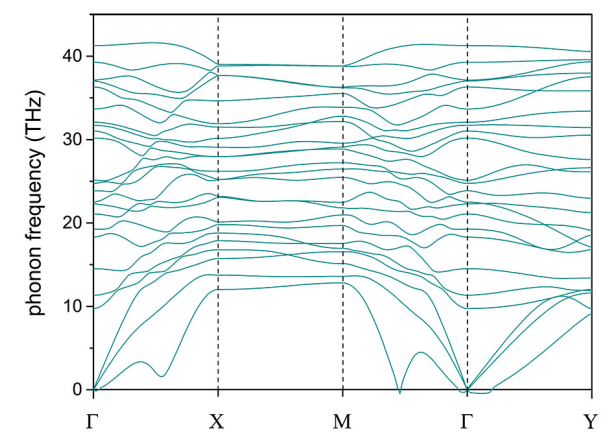

\section{b}

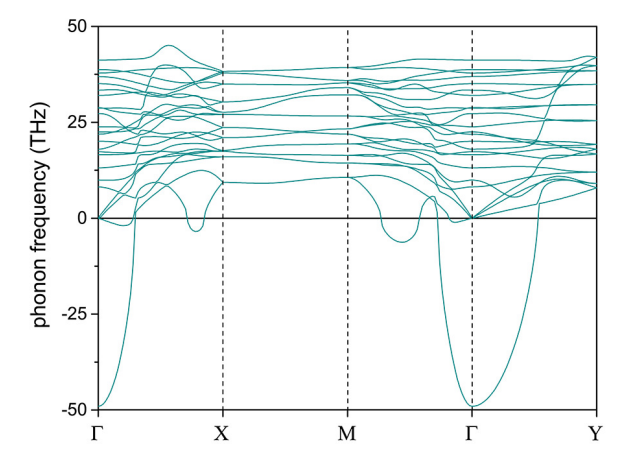

d

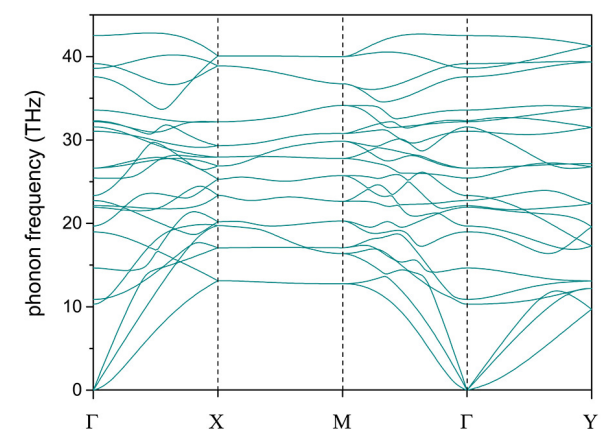

Figure 2. Phonon dispersions of (a) $\mathrm{C}_{8} \mathrm{H}_{4},(\mathbf{b}) \mathrm{C}_{6} \mathrm{~N}_{2},(\mathbf{c}) \mathrm{C}_{5} \mathrm{~N}_{3}$, and (d) $\mathrm{C}_{4} \mathrm{~N}_{4}$. 


\subsection{Electronic Property and Bonding}

In the $\mathrm{sp}^{3}$ 2D carbons, the dangling bonds on their surfaces form energy bands across the Fermi level $\left(\mathrm{E}_{F}\right)$ closing the band gap, but the band gap is open if the dangling bonds are all passivated [11]. For example, the dangling bonds of NCCN and $\mathrm{CNCN}$ phases on the surfaces that are substituted by $\mathrm{N}$ atoms are replaced by lone pair electrons that open the band gap wildly. $\mathrm{C}_{8} \mathrm{H}_{4}$ and $\mathrm{C}_{4} \mathrm{~N}_{4}$ are semiconducting with HSE06 band gap, 3.2 and $3.5 \mathrm{eV}$, respectively, while $\mathrm{C}_{6} \mathrm{~N}_{2}$ and $\mathrm{C}_{5} \mathrm{~N}_{3}$ are metallic. Thus, the band gap of $\mathrm{W}$-diamane is open if no dangling bond is left to be passivated.

The right side of each figure shown in Figure 3 shows the electronic DOS corresponding to the electronic band dispersion on the left side of each structure. $\mathrm{C}_{8} \mathrm{H}_{4}$, where its dangling bonds of $\mathrm{C}_{\mathrm{sf}}$ atoms are fully passivated by $\mathrm{H}$ atoms, has the $\mathrm{p}_{z}$-orbital of $\mathrm{C}_{\mathrm{sf}}$ atoms hybridizing with the s-orbital of $\mathrm{H}$ atoms at energy state $-1 \mathrm{eV}$ below the $\mathrm{E}_{F}$. The electronic density of states (DOS) being occupied near the $\mathrm{E}_{F}$ are of the $\mathrm{p}_{x}$-orbitals of $\mathrm{C}_{\mathrm{sf}}$ atoms in majority and of the $\mathrm{p}_{x}$-orbitals of $\mathrm{C}_{\text {in }}$ next below. $\mathrm{C}_{4} \mathrm{~N}_{4}$, instead fully substituted by $\mathrm{N}$ atoms on the surfaces, has the electronic DOS, which is $\mathrm{C}_{\mathrm{in}}-\mathrm{N}_{\mathrm{sf}}$ hybridization near the $\mathrm{E}_{F}$ in contrast to $\mathrm{C}_{8} \mathrm{H}_{4}$, where its $\mathrm{C}-\mathrm{H}$ hybridization is at a lower energy level. The $\mathrm{p}_{z}$-orbital of $\mathrm{N}_{\mathrm{sf}}$ atoms obviously dominates the valence states near the $\mathrm{E}_{F}$.

The electronic band structures of $\mathrm{C}_{6} \mathrm{~N}_{2}, \mathrm{C}_{5} \mathrm{~N}_{3}$, and $\mathrm{C}_{4} \mathrm{~N}_{4}$ have similar dispersing feature across the reciprocal space (see Figure $3 \mathrm{~b}-\mathrm{d}$ ). One that makes the electronic property of these three structures different is top two valence bands. $\mathrm{C}_{6} \mathrm{~N}_{2}, \mathrm{C}_{5} \mathrm{~N}_{3}$, and $\mathrm{C}_{4} \mathrm{~N}_{4}$ have two, one, and none valence bands, respectively, crossing the $\mathrm{E}_{F}$. Despite that, their valence states are dominated by $\mathrm{p}_{z}$-orbital of $\mathrm{C}_{\mathrm{sf}}$ atoms for $\mathrm{C}_{6} \mathrm{~N}_{2}$ and $\mathrm{C}_{5} \mathrm{~N}_{3}$, and $\mathrm{p}_{z}$-orbital of $\mathrm{N}_{\mathrm{sf}}$ atoms for $\mathrm{C}_{4} \mathrm{~N}_{4}$. This is opposite to the diamane that its partial N-substituted phase, $\mathrm{CNCN}$, has an opening band gap, while the $\mathrm{p}_{z}$-orbital of $\mathrm{C}_{\text {sf }}$ also dominates the valence states [21]. Moreover, the lowest conduction state of $\mathrm{C}_{4} \mathrm{~N}_{4}$ is on a $\Gamma-X$ path, and its highest valence state state is at $\Gamma$ point. Thus, $\mathrm{C}_{4} \mathrm{~N}_{4}$ has an indirect band gap, while $\mathrm{C}_{8} \mathrm{H}_{8}$ has a direct band gap.

a

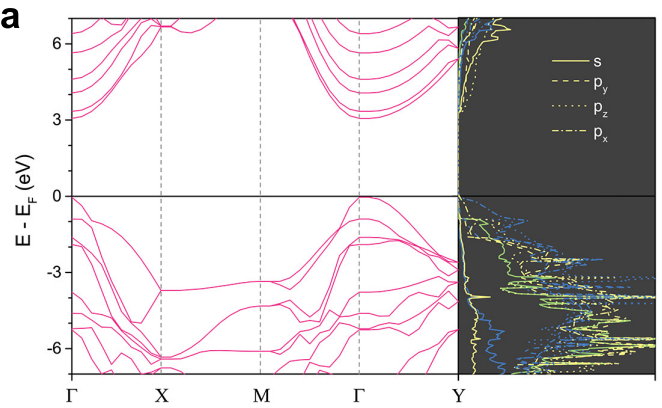

C

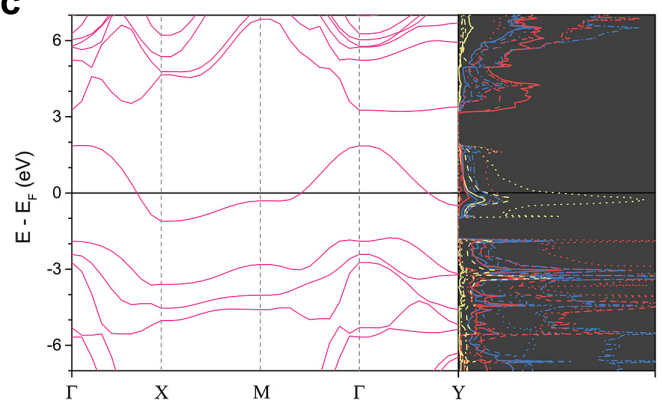

b

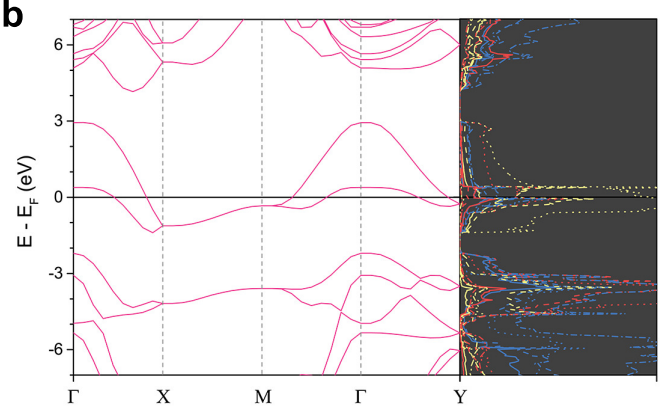

d

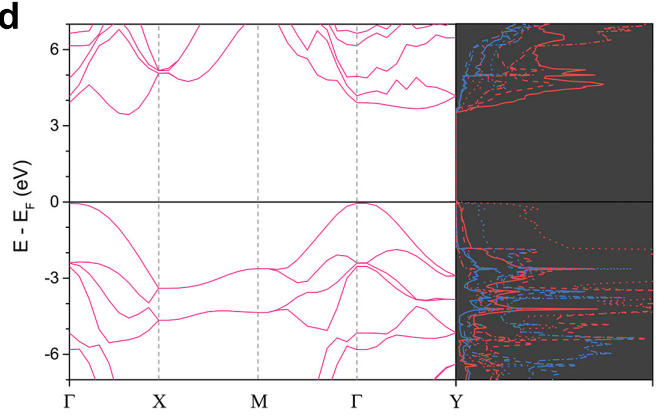

Figure 3. The electronic band dispersions (left) and DOS (right) of (a) $\mathrm{C}_{8} \mathrm{H}_{4},(\mathbf{b}) \mathrm{C}_{6} \mathrm{~N}_{2}$, (c) $\mathrm{C}_{5} \mathrm{~N}_{3}$ and $(\mathbf{d}) \mathrm{C}_{4} \mathrm{~N}_{4}$. The DOS of each atom are presented by blue, yellow, green and red lines for $\mathrm{C}_{\mathrm{in}}, \mathrm{C}_{\mathrm{sf}}, \mathrm{H}$ and $\mathrm{N}$ atoms, respectively. The DOS of each orbital are presented by solid, dashed, dotted, and dash-dotted lines for $\mathrm{s}, \mathrm{p}_{y}, \mathrm{p}_{z}$, and $\mathrm{p}_{x}$ orbitals, respectively. 
It is worth noting that $\mathrm{N}$-substituted $\mathrm{W}$-diamanes have no magnetism, while the $\mathrm{CNCN}$ phase has a tiny magnetization [21]. The magnetism occurs in 2D carbons when the 2D carbons are structurally distorted or defected, for example, hydrogenated graphene, 2D carbon nitrides that are porous structure, diamond surface with Pandey's reconstruction [24,33-37]. The latter needs HSE06 for calculation in order to obtain magnetism [24], while magnetism can be acquired using PBE for the former two [33,34]. However, the Nsubstituted W-diamanes investigated while using PBE and HSE06 are non-magnetism.

\subsection{Elastic Constants}

The hardness is one of the distinguishing properties of diamond and carbon nitrides, where their 2D counterparts are expected to be adopted. However, the hardness of 2D materials, to the best of our knowledge, has not been well-defined. Therefore, the elastic constants that implicitly reflect the hardness are herein considered. Despite the fact that the elastic constants can be calculated by a second derivative of energy with respect to applied strain and devided by a volume of non-strained structure, the 2D materials, such as graphene, are lacking a third dimension. The elastic constants defined for threedimensional (3D) materials are thus reduced to 2D elastic constants [38,39],

$$
C_{i j}^{2 \mathrm{D}}=\frac{1}{A_{0}}\left(\frac{\partial^{2} E\left(\varepsilon_{1}, \ldots, \varepsilon_{6}\right)}{\partial \varepsilon_{i} \partial \varepsilon_{j}}\right)
$$

where $A_{0}$ is an unstrained area of $\mathrm{C}_{1-x} \mathrm{~N}_{x}$, and $\varepsilon_{i}$ is an applied strain up to $\pm 2 \%$ in order to fit the $C_{i j}^{2 D}$. The $2 \mathrm{D}$ elastic constants of $\mathrm{W}$-diamanes are reported in Table 2, by comparing with other 2D sp 3 carbons and carbon nitrides. However, Pakornchote et al. [21] discussed that the 2D elastic constants cannot be used in order to compare across the 2D materials that have different thickness. Therefore, the $2 \mathrm{D}$ elastic constants have to be divided by $d_{0}$ of the 2D materials in order to make the values become intrinsic [21,40],

$$
C_{i j}=\frac{1}{d_{0} A_{0}}\left(\frac{\partial^{2} E\left(\varepsilon_{1}, \ldots, \varepsilon_{6}\right)}{\partial \varepsilon_{i} \partial \varepsilon_{j}}\right),
$$

where $d_{0}$ is reported in Table 1 . The $C_{i j}^{2 \mathrm{D}}$ and $C_{i j}$ are reported in Tables 2 and 3 , respectively.

As the number of $\mathrm{N}$ atoms in the unit cell of $\mathrm{W}$-dimane increasing, the $C_{11}$ of $\mathrm{N}$ substituted W-diamanes are lower, but their $C_{22}$ and $C_{33}$ are higher. Figure 1 shows that, in the $x$ direction, the surficial atoms are bonding with the surficial atoms, which are at the same level, but, in the $y$ direction, the surficial atoms are bonding with the inner atoms, which are at the lower level. Thus, the $\mathrm{N}$ substitution in the surficial layers can enhance (reduce) the stiffness in the direction that the atoms are bonding in the different (same) level. Although, the Voigt bulk modulus $\left(K_{V}\right)$ of $\mathrm{C}_{6} \mathrm{~N}_{2}, \mathrm{C}_{5} \mathrm{~N}_{3}$, and $\mathrm{C}_{4} \mathrm{~N}_{4}$, which are 569 , 553 , and $533 \mathrm{GPa}$, respectively, are approximately the same if they are compared with the $K_{V}$ of NCCN and CNCN phases that are above $600 \mathrm{GPa}$. The result is in accordance with the simulation in Ref. [10], showing that diamane has the tensile strength higher than other conformations. Noting that the $K_{V}$ is typically valid for polycrystals and might not be valid for 2D materials, so the values of $K_{V}$ reported in this work are used for the purpose of comparison.

For $\mathrm{C}_{8} \mathrm{H}_{4}$, its $\mathrm{C}_{i j}$, except $\mathrm{C}_{33}$, are smaller than those of $\mathrm{N}$-substituted $\mathrm{W}$-diamanes. Therefore, $K_{V}$ of $\mathrm{C}_{8} \mathrm{H}_{4}$ is $310 \mathrm{GPa}$, which is much smaller that $K_{V}$ of $\mathrm{C}_{1-x} \mathrm{~N}_{x}$. One might argue that $d_{0}$ of $\mathrm{C}_{8} \mathrm{H}_{4}$ is much larger than $d_{0}$ of $\mathrm{C}_{1-x} \mathrm{~N}_{x}$, so $C_{i j}$ is unsurprisingly small. However, even if we consider $C_{i j}^{2 D}, C_{8} \mathrm{H}_{4}$ has $C_{11}^{2 \mathrm{D}}, C_{12}^{2 \mathrm{D}}, C_{13}^{2 \mathrm{D}}, C_{23}^{2 \mathrm{D}}$, and $C_{66}^{2 \mathrm{D}}$ smaller than $\mathrm{C}_{1-x} \mathrm{~N}_{x}$. The result is in accordance with the result in the H-diamane, which is a fully hydrogenated diamane that its $C_{11}^{2 D}$ and $C_{i j}$ are smaller than that of NCCN and CNCN phases. Thus, it can be concluded that the hydrogenation seem to soften the 2D diamond, while the $\mathrm{N}$ substitution makes the 2D diamond stiffer. 
Table 2. The two-dimensional (2D) elastic constants of four phases of $\mathrm{W}$-diamanes are reported in $\mathrm{N} / \mathrm{m}$ unit by comparing with those of other $2 \mathrm{D} \mathrm{sp}{ }^{3}$ carbons and carbon nitrides.

\begin{tabular}{cccccccc}
\hline Phases & $C_{\mathbf{1 1}}^{2 D}$ & $C_{\mathbf{1 2}}^{2 D}$ & $C_{\mathbf{1 3}}^{2 D}$ & $C_{22}^{2 D}$ & $C_{23}^{2 D}$ & $C_{33}^{2 D}$ & $C_{6 \mathbf{6}}^{2 D}$ \\
\hline $\mathrm{C}_{8} \mathrm{H}_{4}$ & 577 & 41 & 22 & 384 & 8 & 451 & 210 \\
$\mathrm{C}_{6} \mathrm{~N}_{2}$ & 709 & 64 & 27 & 362 & 148 & 300 & 245 \\
$\mathrm{C}_{5} \mathrm{~N}_{3}$ & 666 & 73 & 26 & 392 & 120 & 335 & 256 \\
$\mathrm{C}_{4} \mathrm{~N}_{4}$ & 645 & 71 & 17 & 429 & 87 & 375 & 270 \\
$\mathrm{NCCN}[21]$ & 568 & 66 & 51 & & & 217 & 243 \\
$\mathrm{CNCN} \mathrm{[21]}$ & 526 & 61 & 38 & & & 170 & 220 \\
$\pi$-C $\mathrm{C}_{3} \mathrm{~N}[21]$ & 595 & 106 & 27 & 510 & 16 & 159 & 244 \\
H-diamane [11] & 487 & 38 & & & & & \\
\hline
\end{tabular}

Table 3. The elastic constants and Voigt bulk modulus $\left(K_{V}\right)$ of four phases of W-diamanes are reported in GPa unit by comparing with those of other $2 \mathrm{D} \mathrm{sp}{ }^{3}$ carbons and carbon nitrides.

\begin{tabular}{ccccccccc}
\hline Phases & $C_{\mathbf{1 1}}$ & $\boldsymbol{C}_{\mathbf{1 2}}$ & $\boldsymbol{C}_{\mathbf{1 3}}$ & $\boldsymbol{C}_{\mathbf{2 2}}$ & $\boldsymbol{C}_{\mathbf{2 3}}$ & $\boldsymbol{C}_{\mathbf{3 3}}$ & $\boldsymbol{C}_{\mathbf{6 6}}$ & $\boldsymbol{K}_{\boldsymbol{V}}$ \\
\hline $\mathrm{C}_{8} \mathrm{H}_{4}$ & 1036 & 73 & 40 & 688 & 15 & 810 & 378 & 310 \\
$\mathrm{C}_{6} \mathrm{~N}_{2}$ & 1963 & 177 & 76 & 1002 & 410 & 830 & 678 & 569 \\
$\mathrm{C}_{5} \mathrm{~N}_{3}$ & 1808 & 199 & 71 & 1062 & 3217 & 909 & 694 & 553 \\
$\mathrm{C}_{4} \mathrm{~N}_{4}$ & 1715 & 190 & 56 & 1140 & 226 & 996 & 719 & 533 \\
$\mathrm{NCCN} \mathrm{[21]}$ & 2191 & 253 & 198 & & & 836 & 939 & 718 \\
$\mathrm{CNCN} \mathrm{[21]}$ & 1968 & 227 & 142 & & & 635 & 825 & 618 \\
$\pi$ - $\mathrm{C}_{3} \mathrm{~N}[21]$ & 2030 & 361 & 91 & 1739 & 199 & 541 & 831 & 624 \\
$\mathrm{H}$-diamane [21] & 1026 & 81 & & & & & & \\
\hline
\end{tabular}

Moreover, the elastic constants can be calculated from group velocities of phonons for cross-validation [41]. In the orthorhombic system, the sound waves can be expressed as [42]

$$
\begin{aligned}
& u_{x} \rho \omega^{2}=u_{x}\left[q_{x}^{2} C_{11}+q_{y}^{2} C_{66}+q_{z}^{2} C_{55}\right]+u_{y} q_{x} q_{y}\left(C_{12}+C_{66}\right)+u_{z} q_{x} q_{z}\left(C_{13}+C_{55}\right) \\
& u_{y} \rho \omega^{2}=u_{y}\left[q_{x}^{2} C_{66}+q_{y}^{2} C_{22}+q_{z}^{2} C_{44}\right]+u_{x} q_{x} q_{y}\left(C_{12}+C_{66}\right)+u_{z} q_{y} q_{z}\left(C_{23}+C_{44}\right) \\
& u_{z} \rho \omega^{2}=u_{z}\left[q_{x}^{2} C_{55}+q_{y}^{2} C_{44}+q_{z}^{2} C_{33}\right]+u_{x} q_{x} q_{z}\left(C_{13}+C_{55}\right)+u_{y} q_{y} q_{z}\left(C_{23}+C_{44}\right),
\end{aligned}
$$

where $\mathbf{q}=q_{x} \hat{i}+q_{y} \hat{j}+q_{z} \hat{k}$ is a wave vector, $\mathbf{u}=u_{x} \hat{i}+u_{y} \hat{j}+u_{z} \hat{k}$ is a phonon eigenvector, $\omega(\mathbf{q})=|\mathbf{q}| v_{\left[q_{x} q_{y} q_{z}\right]}$ is a phonon eigenvalue that is limited to acoustic modes, and $\rho$ is a 3D density of W-diamanes. By solving Equations (3)-(5), each $\mathbf{q}$ yields three values of sound velocities, where $[q 00]$ and $[0 q 0]$ are herein considered,

$$
\begin{aligned}
& v_{[q 00]}^{(1)}=\frac{1}{|\mathbf{q}|} \sqrt{\frac{q^{2} C_{11}}{\rho}}, v_{[q 00]}^{(2)}=\frac{1}{|\mathbf{q}|} \sqrt{\frac{q^{2} C_{55}}{\rho}}, v_{[q 00]}^{(3)}=\frac{1}{|\mathbf{q}|} \sqrt{\frac{q^{2} C_{66}}{\rho}} \\
& v_{[0 q 0]}^{(1)}=\frac{1}{|\mathbf{q}|} \sqrt{\frac{q^{2} C_{22}}{\rho}}, v_{[0 q 0]}^{(2)}=\frac{1}{|\mathbf{q}|} \sqrt{\frac{q^{2} C_{44}}{\rho}}, v_{[0 q 0]}^{(3)}=\frac{1}{|\mathbf{q}|} \sqrt{\frac{q^{2} C_{66}}{\rho}} .
\end{aligned}
$$

The above two equations lead to a condition that

$$
v_{[q 00]}^{(3)}=v_{[0 q 0]}^{(3)} .
$$

Superscripts of the velocities are just numbering, but have not yet been assigned to any phonon modes. The sound velocities can be computed from three acoustic phonons while using Phonopy package that takes the derivative on a dynamical matrix with respect to $q$ divided by $2 \omega(\mathbf{q})$ at $q=0.05$. Noting that only $\mathrm{C}_{4} \mathrm{~N}_{4}$ and $\mathrm{C}_{8} \mathrm{H}_{4}$ are discussed, since the 
dispersion of acoustic phonons of $\mathrm{C}_{6} \mathrm{~N}_{2}$ and $\mathrm{C}_{5} \mathrm{~N}_{3}$ are dropping, causing the instability of the structures (see Figure 2).

In Table 4 , the $C_{i j}$ were calculated from the group velocities of three acoustic phonons, $\mathrm{ZA}, \mathrm{TA}$, and LA modes while using Equations (6) and (7). If we assigned $v^{3}$ to be $v^{(T A)}$, this satisfies an unrestricted condition of Equation (8) that $v_{[q 00]}^{T A} \approx v_{[0 q 0]}^{T A}$. Therefore, from Equations (6) and (7), $C_{66}$ is either 725 or $716 \mathrm{GPa}$, which is similar to the $719 \mathrm{GPa}$ of $C_{66}$ that was reported in Table 3. Thus, if we assigned $v^{(1)}$ to be $v^{L A}, C_{11}=\rho\left(v_{[q 00]}^{L A}\right)^{2}=1666 \mathrm{GPa}$ and $C_{22}=\rho\left(v_{[0 q 0]}^{L A}\right)^{2}=1097 \mathrm{GPa}$. These two values are similar to $C_{11}$ and $C_{22}$ reported in Table 3. By these assignments, $C_{i j}$ calculated using Equations (2), (6) and (7) are in correspondence. Noting that, because of a convex dispersion of ZA mode around $\Gamma$-point, $v^{Z A}$ abruptly changes along $\mathbf{q}$, yielding inconsistent values of $C_{44}$ and $C_{55}$, so it needs to be further investigated in the future work.

Table 4. The elastic constants in GPa unit calculated from the group velocities of acoustic phonons at $q=0.05$.

\begin{tabular}{ccccccc}
\hline Phases & $\rho\left(v_{[q 00]}^{Z A}\right)^{2}$ & $\rho\left(v_{[q 00]}^{T A}\right)^{2}$ & $\rho\left(v_{[q 00]}^{L A}\right)^{2}$ & $\rho\left(v_{[0 q 0]}^{Z A}\right)^{2}$ & $\rho\left(v_{[0 q 0]}^{T A}\right)^{2}$ & $\rho\left(v_{[0 q 0]}^{L A}\right)^{2}$ \\
\hline $\mathrm{C}_{8} \mathrm{H}_{4}$ & 102 & 370 & 1003 & 39 & 394 & 692 \\
$\mathrm{C}_{4} \mathrm{~N}_{4}$ & 147 & 725 & 1666 & 60 & 716 & 1097 \\
\hline
\end{tabular}

\subsection{Formation Energy}

An equation that is used to calculate a formation energy is

$$
\Delta E_{\text {form }}\left(\mathrm{C}_{x} \mathrm{~N}_{y}\right)=E\left(\mathrm{C}_{x} \mathrm{~N}_{y}\right)-\frac{x E(\mathrm{C})+y E(\mathrm{~N})}{x+y},
$$

where $E\left(C_{x} \mathrm{~N}_{y}\right)$ is the energy of 2D carbon nitrides, $E(C)$ is an energy of graphene, and $E(\mathrm{~N})$ is an energy of $\mathrm{N}_{2}$ molecule. The formation energies of $\mathrm{N}$-substituted $\mathrm{W}$-diamanes plotted in circle symbols in Figure 4 are 612, 626, and $630 \mathrm{meV}$ for $\mathrm{C}_{6} \mathrm{~N}_{2}, \mathrm{C}_{5} \mathrm{~N}_{3}$, and $\mathrm{C}_{4} \mathrm{~N}_{4}$, respectively. They are relatively high by comparing with the formation energy of synthesizable phases, triazine and polyheptazine [43], which are 171 and $126 \mathrm{meV}$, respectively.

On the one hand, the NCCN phase has the lowest formation energy among 2D diamond-like carbon nitrides. Its formation energy is positive at $0 \mathrm{GPa}$, but the formation energy is on a convex hull at $10 \mathrm{GPa}$ if only layered phases of carbon nitrides are considered. Hence, it is possible to be synthesized if the precursor is limited to be 2D materials [21]. On the other hand, the N-subsituted $\mathrm{W}$-diamanes have the formation energy as triple the NCCN phase (see Figure 4), which is too high for synthesizing such materials. Nw starting materials other than graphene and $\mathrm{N}_{2}$ molecule must be examined in order to find the possible pathway to synthesize $\mathrm{W}$-diamane, but this is beyond the scope of the present work. 


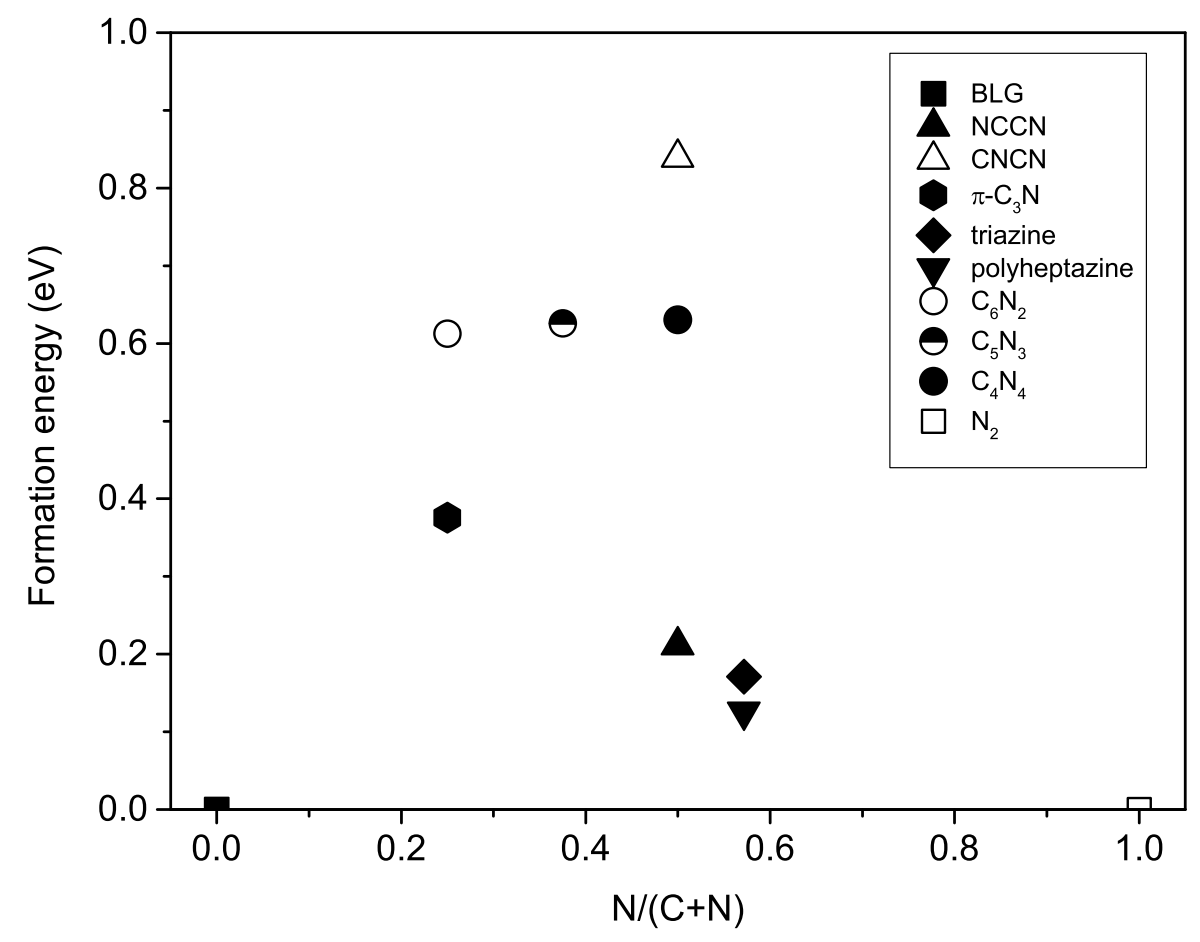

Figure 4. Formation energy of two-dimensional (2D) carbon nitrides is plotted with respect to the $\mathrm{N}$ concentration in the structures, where pure $\mathrm{C}$ phase is graphene and pure $\mathrm{N}$ phase is $\mathrm{N}_{2}$ molecule. The formation energies of $\mathrm{NCCN}, \mathrm{CNCN}, \pi-\mathrm{C}_{3} \mathrm{~N}$, triazine, and polyheptazine phases are from Ref. [21].

\section{Conclusions}

We have shown that the stiffness and $K_{V}$ of $\mathrm{N}$-substituted W-diamane increase with the $\mathrm{N}$ content. The band gap of $\mathrm{W}$-diamane is only open if the $\mathrm{N}$ atoms are entirely substituted on two surfaces. Even though their formation energies is positive when evaluated with respect to graphene and N2 molecule, which are both assumed to be precursors for Wdiamane in the present work, the $\mathrm{N}$-containing diamane is likely to possess higher stiffness than that of (hydrogenated) diamane. However, further investigation regarding a possible pathway to fabricate $\mathrm{N}$-containing diamane, such as $\mathrm{W}$-diamane, must be deserved in order to serve as guidelines for furture experimental synthesis of the material.

Author Contributions: T.P. and T.B. designed the research; T.P., A.E. and U.P. performed the research; All authors analysed the data; T.P. and T.B. wrote the manuscript. All authors have read and agreed to the published version of the manuscript.

Funding: This project is funded by National Research Council of Thailand (NRCT): (NRCT5RSA63001-04). This research is partially funded by Chulalongkorn University; Grant for Research.

Data Availability Statement: Not applicable.

Acknowledgments: This research project was supported by the Second Century Fund (C2F), Chulalongkorn University. This project is funded by National Research Council of Thailand (NRCT): (NRCT5-RSA63001-04). This research is partially funded by Chulalongkorn University; Grant for Research.

Conflicts of Interest: The authors declare no conflict of interest. 


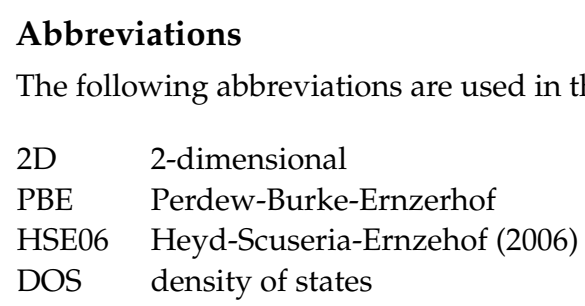

\section{References}

1. Lee, C.; Wei, X.; Kysar, J.W.; Hone, J. Measurement of the Elastic Properties and Intrinsic Strength of Monolayer Graphene. Science 2008, 321, 385-388. [CrossRef] [PubMed]

2. Wang, S.Q.; Ye, H.Q. Ab initio elastic constants for the lonsdaleite phases of C, Si and Ge. J. Phys. Condens. Matter 2003, 15, 5307. [CrossRef]

3. Németh, P.; Garvie, L.A.J.; Aoki, T.; Dubrovinskaia, N.; Dubrovinsky, L.; Buseck, P.R. Lonsdaleite is faulted and twinned cubic diamond and does not exist as a discrete material. Nat. Commun. 2014, 5, 5447. [CrossRef]

4. McCulloch, D.G.; Wong, S.; Shiell, T.B.; Haberl, B.; Cook, B.A.; Huang, X.; Boehler, R.; McKenzie, D.R.; Bradby, J.E. Investigation of Room Temperature Formation of the Ultra-Hard Nanocarbons Diamond and Lonsdaleite. Small 2020, 16, 2004695. [CrossRef]

5. Barboza, A.P.M.; Guimaraes, M.H.D.; Massote, D.V.P.; Campos, L.C.; Neto, N.M.B.; Cancado, L.G.; Lacerda, R.G.; Chacham, H.; Mazzoni, M.S.C.; Neves, B.R.A. Room-Temperature Compression-Induced Diamondization of Few-Layer Graphene. Adv. Mater. 2011, 23, 3014-3017. [CrossRef]

6. Martins, L.G.P.; Matos, M.J.S.; Paschoal, A.R.; Freire, P.T.C.; Andrade, N.F.; Aguiar, A.L.; Neves, B.R.A.; de Oliveira, A.B.; Mazzoni, M.S.C.; Filho, A.G.S.; et al. Raman evidence for pressure-induced formation of diamondene. Nat. Commun. 2017, 8, 96. [CrossRef]

7. Leenaerts, O.; Partoens, B.; Peeters, F.M. Hydrogenation of bilayer graphene and the formation of bilayer graphane from first principles. Phys. Rev. B 2009, 80, 245422. [CrossRef]

8. Samarakoon, D.K.; Wang, X.Q. Tunable Band Gap in Hydrogenated Bilayer Graphene. ACS Nano 2010, 4, 4126-4130. [CrossRef]

9. Chernozatonskii, L.A.; Sorokin, P.B.; Kvashnin, A.G.; Kvashnin, D.G. Diamond-Like C2H Nanolayer, Diamane: Simulation of the Structure and Properties. JETP Lett. 2009, 90, 134-138. [CrossRef]

10. Gao, Y.; Cao, T.; Cellini, F.; Berger, C.; de Heer, W.A.; Tosatti, E.; Riedo, E.; Bongiorno, A. Ultrahard carbon film from epitaxial two-layer graphene. Nat. Nanotechnol. 2018, 13, 133-138. [CrossRef]

11. Pakornchote, T.; Ektarawong, A.; Alling, B.; Pinsook, U.; Tancharakorn, S.; Busayaporn, W.; Bovornratanaraks, T. Phase stabilities and vibrational analysis of hydrogenated diamondized bilayer graphenes: A first principles investigation. Carbon 2019, 146, 468-475. [CrossRef]

12. Kvashnin, A.G.; Sorokin, P.B. Lonsdaleite Films with Nanometer Thickness. J. Phys. Chem. Lett. 2014, 5, 541-548. [CrossRef]

13. Kvashnin, A.G.; Avramov, P.P.V.; Kvashnin, D.G.K.; Chernozatonskii, L.A.; Sorokin, P.B. Features of Electronic, Mechanical, and Electromechanical Properties of Fluorinated Diamond Films of Nanometer Thickness. J. Phys. Chem. C 2017, 121, 28484-28489. [CrossRef]

14. Pimenta Martins, L.G.; Silva, D.L.; Smith, J.S.; Lu, A.Y.; Su, C.; Hempel, M.; Occhialini, C.; Ji, X.; Pablo, R.; Alencar, R.S.; et al. Hard, transparent, sp3-containing 2D phase formed from few-layer graphene under compression. Carbon 2021, 173, 744-757. [CrossRef]

15. Zhu, L.; Li, W.; Ding, F. Giant thermal conductivity in diamane and the influence of horizontal reflection symmetry on phonon scattering. Nanoscale 2019, 11, 4248-4257. [CrossRef]

16. Raeisi, M.; Mortazavi, B.; Podryabinkin, E.V.; Shojaei, F.; Zhuang, X.; Shapeev, A.V. High thermal conductivity in semiconducting Janus and non-Janus diamanes. Carbon 2020, 167, 51-61. [CrossRef]

17. Piazza, F.; Gough, K.; Monthioux, M.; Puech, P.; Gerber, I.; Wiens, R.; Paredes, G.; Ozoria, C. Low temperature, pressureless sp ${ }^{2}$ to $\mathrm{sp}^{3}$ transformation of ultrathin, crystalline carbon films. Carbon 2019, 145, 10-22. [CrossRef]

18. Piazza, F.; Monthioux, M.; Puech, P.; Gerber, I. Towards a better understanding of the structure of diamanoïds and diamanoïd/graphene hybrids. Carbon 2020, 156, 234-241. [CrossRef]

19. Piazza, F.; Cruz, K.; Monthioux, M.; Puech, P.; Gerber, I. Raman evidence for the successful synthesis of diamane. Carbon 2020, 169, 129-133. [CrossRef]

20. Bakharev, P.V.; Huang, M.; Saxena, M.; Lee, S.W.; Joo, S.H.; Park, S.O.; Dong, J.; Camacho-Mojica, D.C.; Jin, S.; Kwon, Y.; et al. Chemically induced transformation of chemical vapour deposition grown bilayer graphene into fluorinated single-layer diamond. Nat. Nanotechnol. 2020, 15, 59-66. [CrossRef]

21. Pakornchote, T.; Ektarawong, A.; Busayaporn, W.; Pinsook, U.; Bovornratanaraks, T. Roles of nitrogen substitution and surface reconstruction in stabilizing nonpassivated single-layer diamond. Phys. Rev. B 2020, 102, 075418. [CrossRef]

22. Pandey, K.C. New dimerized-chain model for the reconstruction of the diamond (111)- $(2 \times 1)$ surface. Phys. Rev. B 1982, 25,4338 . [CrossRef]

23. Iarlori, S.; Galli, G.; Gygi, F.M.C.; Parrinello, M.; Tosatti, E. Reconstruction of the diamond (111) surface. Phys. Rev. Lett. 1992, 69, 2947-2950. [CrossRef] 
24. Pamuk, B.; Calandra, M. Exchange-driven dimerization, magnetism, and insulating state in diamond (111). Phys. Rev. B 2019, 99, 155303. [CrossRef]

25. Artyukhov, V.I.; Chernozatonskii, L.A. Structure and Layer Interaction in Carbon Monofluoride and Graphane: A Comparative Computational Study. J. Phys. Chem. A 2010, 114, 5389-5396. [CrossRef]

26. Kresse, G.; Furthmüller, J. Efficiency of ab-initio total energy calculations for metals and semiconductors using a plane-wave basis set. Comput. Mater. Sci. 1996, 6, 15. [CrossRef]

27. Kresse, G.; Furthmüller, J. Efficient iterative schemes for ab initio total-energy calculations using a plane-wave basis set. Phys. Rev. B 1996, 54, 11169. [CrossRef]

28. Blöchl, P.E. Projector augmented-wave method. Phys. Rev. B 1994, 50, 17953. [CrossRef]

29. Perdew, J.P.; Burke, K.; Ernzerhof, M. Generalized Gradient Approximation Made Simple. Phys. Rev. Lett. 1996, 77, 3865. [CrossRef]

30. Krukau, A.V.; Vydrov, O.A.; Izmaylov, A.F.; Scuseria, G.E. Influence of the exchange screening parameter on the performance of screened hybrid functionals. J. Chem. Phys. 2006, 125, 224106. [CrossRef]

31. Togo, A.; Tanaka, I. First principles phonon calculations in materials science. Scr. Mater. 2015, 108, 1-5. [CrossRef]

32. Blöchl, P.E.; Jepsen, O.; Andersen, O.K. Improved tetrahedron method for Brillouin-zone integrations. Phys. Rev. B 1994, 49, 16223. [CrossRef] [PubMed]

33. Sofo, J.O.; Usaj, G.; Cornaglia, P.S.; Suarez, A.M.; Hernández-Nieves, A.D.; Balseiro, C.A. Magnetic structure of hydrogen-induced defects on graphene. Phys. Rev. B 2012, 85, 115405. [CrossRef]

34. Rudenko, A.N.; Keil, F.J.; Katsnelson, M.I.; Lichtenstein, A.I. Exchange interactions and frustrated magnetism in single-side hydrogenated and fluorinated graphene. Phys. Rev. B 2013, 88, 081405. [CrossRef]

35. Zhang, Y.; Li, S.Y.; Huang, H.; Li, W.T.; Qiao, J.B.; Wang, W.X.; Yin, L.J.; Bai, K.K.; Duan, W.; He, L. Scanning Tunneling Microscopy of the $\pi$ Magnetism of a Single Carbon Vacancy in Graphene. Phys. Rev. Lett. 2016, 117, 166801. [CrossRef]

36. Bu, S.; Yao, N.; Hunter, M.A.; Searles, D.J.; Yuan, Q. Design of two-dimensional carbon-nitride structures by tuning the nitrogen concentration. Npj Comput. Mater. 2020, 6, 128. [CrossRef]

37. Bafekry, A.; Neek-Amal, M.; Peeters, F.M. Two-dimensional graphitic carbon nitrides: Strain-tunable ferromagnetic ordering. Phys. Rev. B 2020, 101, 165407. [CrossRef]

38. Wei, X.; Fragneaud, B.; Marianetti, C.A.; Kysar, J.W. Nonlinear elastic behavior of graphene: Ab initio calculations to continuum description. Phys. Rev. B 2009, 80, 205407. [CrossRef]

39. Ding, Y.; Wang, Y. Density Functional Theory Study of the Silicene-like SiX and XSi3 (X = B, C, N, Al, P) Honeycomb Lattices: The Various Buckled Structures and Versatile Electronic Properties. J. Phys. Chem. C 2013, 117, 18266-18278. [CrossRef]

40. Wei, Q.; Peng, X. Superior mechanical flexibility of phosphorene and few-layer black phosphorus. Appl. Phys. Lett. 2014, 104, 251915. [CrossRef]

41. Chernozatonskii, L.A.; Sorokin, P.B.; Kuzubov, A.A.; Sorokin, B.P.; Kvashnin, A.G.; Kvashnin, D.G.; Avramov, P.V.; Yakobson, B.I. Influence of Size Effect on the Electronic and Elastic Properties of Diamond Films with Nanometer Thickness. J. Phys. Chem. C 2011, 115, 132-136. [CrossRef]

42. Mahan, G.D. Condensed Matter in a Nutshell; Princeton University Press: Princeton, NJ, USA, 2011.

43. Miller, T.S.; Jorge, A.B.; Suter, T.M.; Sella, A.; Corà, F.; McMillan, P.F. Carbon nitrides: Synthesis and characterization of a new class of functional materials. Phys. Chem. Chem. Phys. 2017, 19, 15613-15638. [CrossRef] [PubMed] 